\title{
sciendo
}

\section{EFFECT OF PARITY ON CLAW HORN LESIONS IN HOLSTEIN DAIRY COWS: CLINICAL AND RADIOLOGICAL STUDY*}

\author{
Enrico Fiore ${ }^{1}$, Laura Perillo², Giorgio Marchesini ${ }^{1}$, Giuseppe Piccione ${ }^{2 \bullet}$, Elisabetta Giudice ${ }^{3}$, \\ Alessandro Zumbo ${ }^{2}$, Leonardo Armato ${ }^{1}$, Giorgia Fabbri' ${ }^{1}$, Matteo Gianesella ${ }^{1}$ \\ ${ }^{1}$ Department of Animal Medicine, Productions and Health (MAPS) - University of Padua, \\ Viale dell'Università 16, 35020, Legnaro (PD), Italy \\ ${ }^{2}$ Department of Veterinary Science, University of Messina, Polo Universitario dell'Annunziata, \\ 98168, Messina, Italy \\ ${ }^{3}$ Department of Chemical, Biological, Pharmaceutical and Environmental Sciences, University \\ of Messina, Viale Ferdinando Stagno d'Alcontres 31, 98166, S. Agata (ME), Italy \\ 'Corresponding author: gpiccione@unime.it
}

\begin{abstract}
The aim of this study was to estimate the effect of parity on claw lesions prevalence in Holstein dairy cows through clinical and radiological observations. Ninety-seven cows were examined two months after calving to record body condition score, locomotion score, feet diagnostic imaging (X-ray), hoof trimming and clinical evaluation. According to the lactation, the cows were divided into three groups: first parity (Group 1, $n=40$ ), second parity (Group 2, $n=29$ ) and third or more parity (Group 3, n=28). Several claw lesions were found. One-way analysis of variance was applied along with Pearson's correlation coefficient. Significant effect of groups was evidenced on radiographic images. In particular, the radiographic images showed a significant increase of osteolysis from Group 1 to Group 3. The application of Pearson's correlation coefficient showed a significantly positive correlation between locomotion score and some claw lesions in all groups. In conclusion, this study provides an overview of claw lesions in dairy cow through clinical and radiological observations.
\end{abstract}

Key words: dairy cow, parity, locomotion score, radiology, claw lesions

Feet and leg diseases are a persistent but not decreasing problem in modern intensive dairy production (Guccione et al., 2016; Schöpke et al., 2013). Disorders of the bovine hoof, known as claw disorders, can be very painful and often cause lameness compromising cow welfare and reducing lifespan and productivity (Fiore et al., 2016; Häggman and Juga, 2015; Schöpke et al., 2013). However, at the time of hoof trimming, subclinical cases can often be recognized allowing early action

\footnotetext{
*The research was funded by University of Padua, CPDA134009/13.
} 
to be taken. Meanwhile, routine hoof trimming allows for targeted data collection (Schöpke et al., 2013). Claw disorders cause approximately 90\% of lameness cases in dairy cattle with no indication of abnormal locomotion (Olechnowicz et al., 2010 a). Lameness is a major welfare problem for its detection difficulties, because cattle with claw-horn disease do not show lameness unless the lesion causes significant pain and discomfort (Chesterton et al., 2008). Some studies have paid particular attention to the metabolic alterations associated with changes on claw tissue around calving (Momcilovic et al., 2000). Lameness and claw lesions have been shown to be caused by several risk factors such as parity and lactation stage together with the potential exacerbation of disease by nutritional and mechanical influences (Sogstad et al., 2005). In the pathogenesis of claw lesions herd-level factors including housing environment, management practices, season of claw trimming and nutrition, as well as cow-level factors including parity, lactation rank, milk yield, lactation stage, body weight, breed and genetics are involved (Katsoulos and Christodoulopoulos 2009; Olechnowicz et al., 2010 a). Some authors stated that the percentage of cows with no diagnosed claw disorders in terms of parity from 1 to 4 was $92.6 \%, 94.2 \%$, 93.7\%, and 90.5\% respectively (Olechnowicz et al., 2010 a). Laminitis-related claw lesions are caused by metabolic disorders, in which nutritional and hormonal changes around calving are important in the aetiology (Fjeldaas et al., 2011). Nutrition is an important factor, both by maintaining the quality of the horn through vitamins and trace elements such as biotin, or through a relationship with subacute ruminal acidosis. Hormonal modifications in the transition period seem to be related with non-inflammatory changes in the connective tissue of the corium that damage the flexibility of the feet to external stresses, facilitated through the activation of certain gelatinoproteases (Cook and Nordlund, 2009). External trauma can result in claw traumatic injuries or reduce the sole thickness due to excessive wear (Cook and Nordlund, 2009). Infectious agents, such as Fusobacterium necrophorum and several species of Treponema spp, have been associated with infectious lesions of the claw (Cook and Nordlund, 2009). They are partly contagious, with poor hygiene and claws contamination by manure and urine as important predisposing factors (Fjeldaas et al., 2011). The daily level of cows' activity has been demonstrated to be indicative of animals' physiological and health status, therefore giving secondary information about their well-being and benefit. Modifications in activities such as movement and resting, can mirror problems in the herd, and could be linked to decreased productivity of the calves (Brzozowska et al., 2014). For these reasons, cows would be "locomotion scored". These scores comprise a category for 'imperfect locomotion' or 'uneven gait' to describe a cow that is sick (favouring one leg) but not clinically lame (Green et al., 2002). It has been shown that cows with healthy feet walk more quickly and with wider steps than cows with severe claw disorders do (Fjeldaas et al., 2011). In view of such consideration, the aim of this study was to estimate the effect of parity on the prevalence of claw lesions in Holstein dairy cows through clinical and radiological observations. 


\section{Material and methods}

\section{Animals and housing}

The study was carried out in a confinement Italian dairy herd located in North Italy $\left(45^{\circ} 38^{\prime} \mathrm{N} ; 10^{\circ} 87^{\prime} \mathrm{E}\right)$ at an altitude of $68 \mathrm{~m}$. The selected farm had 200 cows in lactation with a milk production of about $10,000 \mathrm{~kg}$ per year per cow. One hundred eighty-two cubicles were present in the farm. The cubicle surfaces were equipped with a rubber mattress. The flooring area in the dry group was covered with straw; the lactation group was located on rubber mat ( $5 \mathrm{~cm}$ of thickness). All animals were fed using a total mixed ration (TMR) and received a steaming-up diet for 15 days in the final part of the dry period. Water was freely available from constant-level troughs. A routine maintenance claw-trimming scheme in the farm was carried out twice in a year, at $70 \pm 15$ days before and at $50 \pm 15$ days after calving. Scheduled hoof trimming sessions were recorded by a professional veterinarian claw trimmer two months before calving. During the two hoof trimming treatments, all cows were placed in an upright chute equipped with a head gate and a manually operated rope foot lift. Each limb was raised with a rope fastened mid-diaphysis of the third metatarsal bone. All feet were cleaned and trimmed to remove stained, overgrown hoof horn tissue following guidelines of the functional hoof trimming method (Toussaint Raven, 1989); one leg at a time was raised to preserve as much as possible the welfare of animals and reduce their stress during trimming sessions.

\section{Experimental design}

The study took place from September 2014 to March 2015. Ninety-seven Holstein Friesian dairy cows were examined to record body condition score (BCS), locomotion score, hoof trimming, clinical evaluation and feet diagnostic imaging two months after calving. The cows were divided into three groups according to the stage of parity: first parity (Group 1, n=40), second parity (Group 2, n= 29) and third or more parity (Group 3, n=28). BCS measure was always performed by the same operator and was determined in each subject according to Edmonson et al. (1989) using a 5-point scale with quarter-point increments.

\section{Locomotion scoring}

The locomotion score was evaluated for each cow. According to Rajkondawar et al. (2006), all cows were observed in standing position and walking in a straight line. A score of 1 to 5 ( 1 = healthy; $5=$ severely lame) was assigned for each limb. If two limbs of the same cow were lame, the total scoring result of the cow was considered to be the worst of the two singular limb scores. After locomotion score evaluation, cows were placed in an upright chute equipped with a head gate and a manually operated rope foot lift in order to perform diagnostic imaging (X-ray).

\section{Hoof trimming and evaluation for claw lesions}

Immediately after clinical and radiographic examination, all cows were trimmed, in order to show any defect, and all skin and horn lesions related to the distal part of both hind limbs were recorded following the Dairy Claw Lesion identification 
scheme co-developed by Zinpro Performance Minerals and The International Lameness Committee (Mülling et al., 2014). All lesions were classified according to Rajkondawar et al. (2006), scored for severity, measured to determine size, and taken a picture. Lesions included: white line lesion (WLL), sole ulcer (SU), sole haemorrhage ( $\mathrm{SH}$ ), toe ulcer (TU), corkscrew claw (CC), horizontal fissure or hardship groove (HF), vertical fissure (VF), axial fissure (AF), interdigital hyperplasia (IDH), thin sole (TS), digital dermatitis (DD), heel erosion (HE), interdigital dermatitis (ID) and foot rot, foul or phlegmon (F). Every lesion found and the locomotion scores were reported on a clinical schedule. The individual cow was scored as 1 (affected) if one or both hoofs showed disorders, or as 0 otherwise. A recording of more than one disorder was possible. Score 1 included subclinical and clinical cases. After identification, all lesions got the usual treatment: therapeutic trimming, shoe, bandage, cleaning and/or dressing with disinfecting products depending on the lesion type.

\section{Radiographic evaluation}

Radiographic evaluation was carried out from the foot region to the hind limbs. Each cow was assessed to ensure they were able to stand. A diagnostic portable Xray unit (AJEX140H, AJEX Meditech, Ldt., Korea) with Carestream CR Pannell Phosphor screens $24 \times 30 \mathrm{~cm}$ was used in the study. Images were acquired with a digital portable scanner (DirectView Vita-CR, Carestream Health Inc., NY USA) just after they were taken. To permit that images could be taken with marginal restraint of the cow a long handled radiographic panel holder was used to guarantee that the right location and angle to the central beam could be provided without movement. The following projections were used for each distal limb: latero-medial (LM) and dorsopalmar (DP). LM projection was taken maintaining the animal in standing position, conscious and weight bearing on all four limbs while in order to take DP projection the foot was raised with a rope fastened mid-diaphysis of the third metatarsal bone. Before taking the radiographic images, each leg and foot was cleaned to take any potential artefacts away. An exposure of $60-64 \mathrm{kVp}$ and $6.40 \mathrm{mAs}$ and a consistent film focus distance $100 \mathrm{~cm}$ were used during the process. The radiographic images were imported into the Carestream Image Suite image processing software (Ver 4.0, Carestream Inc., USA). Each image was recorded and stored along with the image number, the cow identity, limb and right or left feet view. The radiographic results were classified according to the different degree of the distal phalanx osteolysis and any pathological fracture. The percentage of osteolysis affecting the pedal bone was estimated in the dorsopalmar/plantar projections. Osteolysis was classified as slight (when only affecting the dorsal margin) and as up to a quarter, one-third, a half and up to two-thirds of the pedal bone (Figure 1) as reported by Kofler (1999).

\section{Statistical analysis}

All data were transcribed to Excel and descriptive analysis was performed on lesion type and lesion location data. The obtained data were expressed as Mean \pm Standard Deviation (SD). Data were normally distributed (Shapiro and Wilk test). The Chi-square ( $\chi 2)$ test was used to assess the increase in osteolysis with Groups. One-way analysis of variance (ANOVA) was applied to assess the statistical sig- 
nificance among the three groups on WLL, SU, SH, TU, CC, HF, VF, AF, IDH, TS, DD, HE, ID, F, right hind limb medial phalanx X-ray, right hind limb lateral phalanx $\mathrm{X}$-ray, left hind limb medial phalanx X-ray and left hind limb lateral phalanx X-ray. Bonferroni's multiple comparison test was used for post hoc comparison test. P values $<0.05$ were considered statistically significant. Pearson's correlation coefficient was determined to assess the relationship between locomotion score and other variables. Statistical analysis was performed using the STATISTICA software package (STATISTICA 7 Stat Software Inc., Tulsa, Oklahoma).

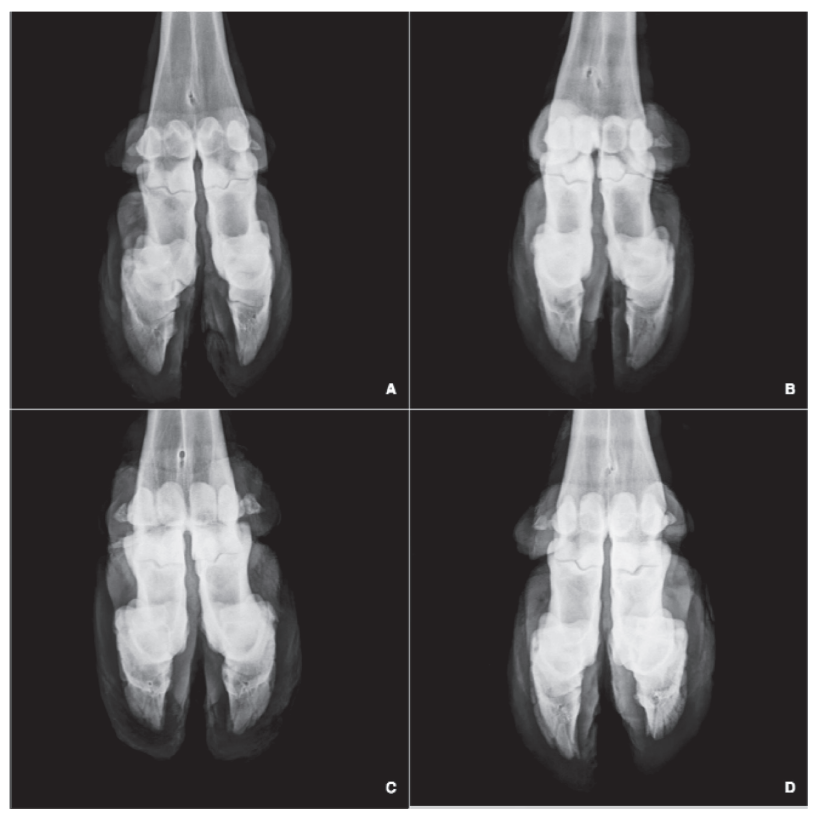

Figure 1. Dorso-plantar radiographs of the claws of the left or right hind limb of the studied cows. The radiographs exhibit: no osteolysis (A); osteolysis of grade 1 in the left phalanx and osteolysis of grade 2 in the right phalanx (B); osteolysis of grade 3 in the left phalanx and osteolysis of grade 4 in the right phalanx (C); osteolysis of grade 5 in the left phalanx and osteolysis of grade 6 in the right phalanx (D)

\section{Results}

Prevalence of claw disorders is shown in Figure 2. Lesions were absent in 3 cows of Group 1, in 4 cows of Group 2 and in 1 cow of Group 3. TU and IDH were not found in any group, instead, CC, VF and HE were found only in Group 1 in a very low percentage and IDH only in Group 3, also in a very low percentage. Chi-square did not show any significant statistical increase in osteolysis with Groups. Table 1 shows the number of cows affected by claw disorders with the different degree of osteolysis affecting the pedal bone. The radiographic images showed an increase of osteolysis from Group 1 to Group 3. In particular, it was evidenced that lateral phalanges were more affected by osteolysis than medial ones and sometimes the two phalanges of the same feet were affected to a different degree. Percentage of osteoly- 
sis affecting the pedal bone is shown in Figure 3. Locomotion score ranged from 1 to 3 in all groups. In particular, in Group 1 the mean value was $1.65 \pm 0.62$, in Group 2 $1.69 \pm 0.76$ and in Group $31.86 \pm 0.65$. One-way ANOVA showed a significant effect of groups $(\mathrm{P}<0.05)$ on the following data: right hind limb medial phalanx $\mathrm{X}$-ray, right hind limb lateral phalanx X-ray and left hind limb medial phalanx X-ray. The application of Bonferroni's post-hoc comparison showed statistically lower right and left hind limb medial phalanx X-ray values in Group 1 compared to Group $3(\mathrm{P}<0.05)$, whereas right hind limb lateral phalanx X-ray was lower in Group 1 compared to Groups 2 and $3(\mathrm{P}<0.005)$ (Figure 4). The application of Pearson's correlation coefficient showed a significantly positive correlation between locomotion score and VF $(\mathrm{r}=0.3518, \mathrm{P}=0.026)$ in Group 1; locomotion score and DD $(\mathrm{r}=0.5674, \mathrm{P}=0.001)$ in Group 2; locomotion score and AF ( $\mathrm{r}=0.4961, \mathrm{P}=0.007)$, DD $(\mathrm{r}=0.4389, \mathrm{P}=0.019)$ and ID ( $\mathrm{r}=0.4323, \mathrm{P}=0.022)$ in Group 3 (Table 2 ).

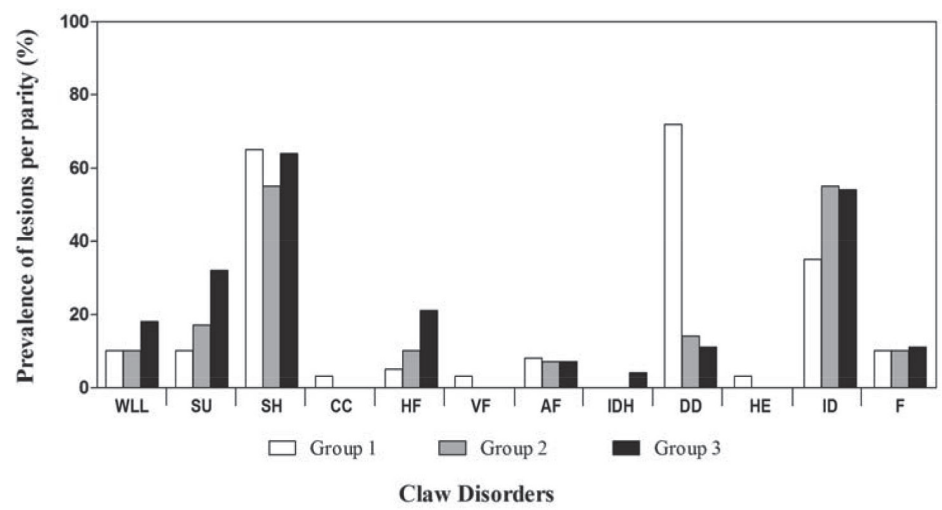

Figure 2. Incidence of claw disorders in Group 1 (first parity cows), Group 2 (second parity cows) and Group 3 (third or more parity cows). White line lesion (WLL), sole ulcer (SU), sole haemorrhage (SH), corkscrew claw (CC), horizontal fissure or hardship groove (HF), vertical fissure (VF), axial fissure (AF), interdigital hyperplasia (IDH), digital dermatitis (DD), heel erosion (HE), interdigital dermatitis (ID) and foot rot, foul or phlegmon (F)

Table 1. Number of cows affected by claw disorders with the different degree of osteolysis affecting the pedal bone. White line lesion (WLL), sole ulcer (SU), sole haemorrhage (SH), corkscrew claw (CC), horizontal fissure or hardship groove (HF), vertical fissure (VF), axial fissure (AF), interdigital hyperplasia (IDH), digital dermatitis (DD), heel erosion (HE), interdigital dermatitis (ID) and foot rot, foul or phlegmon (F). (0) No evidence of osteolysis. (1) Slight osteolysis of the apex. (2) Osteolysis of up to one quarter. (3) Osteolysis of up to one third. (4) Osteolysis of up to a half. (5) Osteolysis of up to two thirds. (6) Widespread osteolysis

\begin{tabular}{c|c|c|c|c|c|c|c|c|c|c|r|r}
\hline Osteolysis & WLL & SU & SH & CC & HF & VF & AF & IDH & DD & HE & ID & F \\
\hline 0 & 0 & 0 & 1 & 0 & 0 & 0 & 0 & 0 & 0 & 0 & 1 & 0 \\
1 & 1 & 2 & 7 & 0 & 1 & 0 & 0 & 0 & 3 & 0 & 0 & 0 \\
2 & 5 & 2 & 15 & 0 & 3 & 0 & 3 & 0 & 2 & 1 & 13 & 1 \\
3 & 1 & 4 & 10 & 1 & 1 & 0 & 1 & 0 & 4 & 0 & 8 & 1 \\
4 & 5 & 4 & 13 & 0 & 3 & 1 & 3 & 1 & 2 & 0 & 13 & 3 \\
5 & 2 & 3 & 11 & 0 & 2 & 0 & 0 & 0 & 5 & 0 & 6 & 3 \\
6 & 1 & 2 & 3 & 0 & 1 & 0 & 0 & 0 & 0 & 0 & 2 & 1 \\
\hline
\end{tabular}



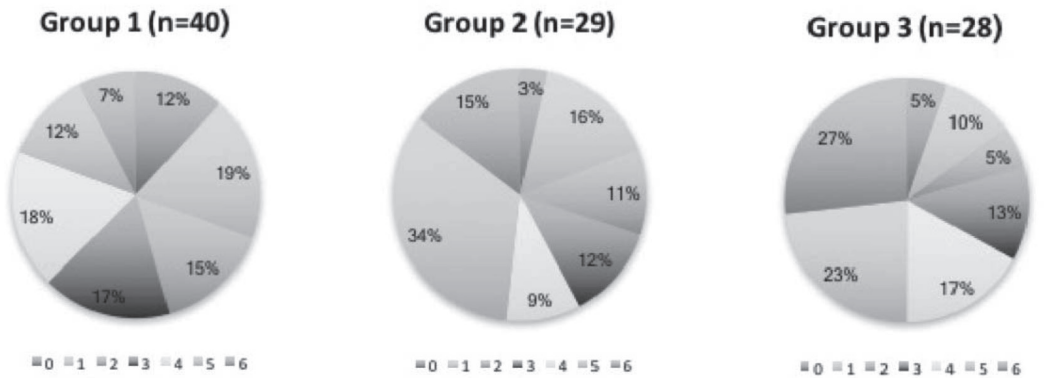

Figure 3. Percentage of osteolysis affecting the pedal bone in Group 1 (first parity cows), Group 2 (second parity cows) and Group 3 (third or more parity cows). (0) No evidence of osteolysis. (1) Slight osteolysis of the apex. (2) Osteolysis of up to one quarter. (3) Osteolysis of up to one third. (4) Osteolysis of up to a half. (5) Osteolysis of up to two thirds. (6) Widespread osteolysis
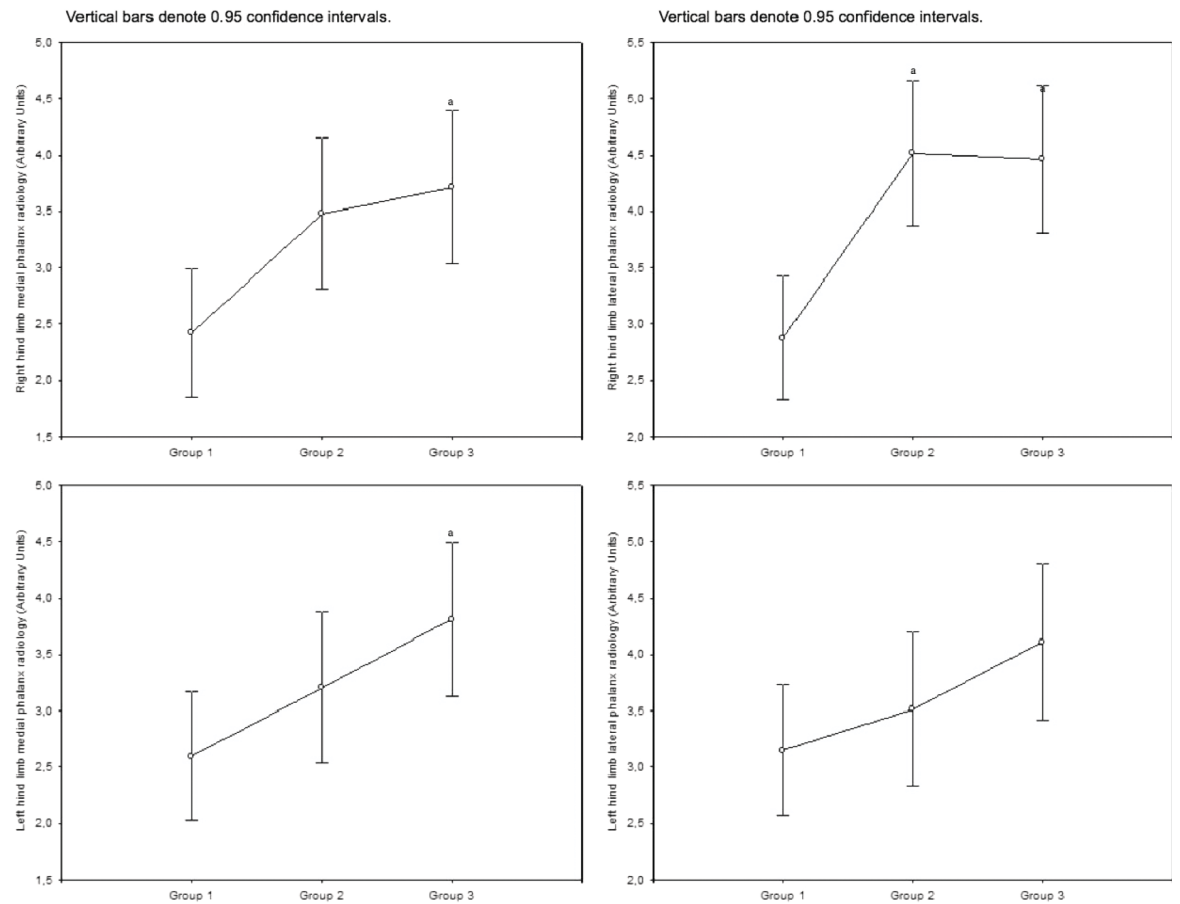

Significances among experimental Groups: a vs Group 1

Figure 4. Trend of the right hind limb medial phalanx X-ray, right hind limb lateral phalanx X-ray and left hind limb medial phalanx X-ray with the statistical significances $(\mathrm{P}<0.05)$ obtained in Group 1 (first parity cows), Group 2 (second parity cows) and Group 3 (third or more parity cows) 
Table 2. Coefficients of correlation between locomotion score and right hind limb medial phalanx X-ray, right hind limb lateral phalanx X-ray, left hind limb medial phalanx X-ray, left hind limb lateral phalanx X-ray and claw lesions calculated for Group 1 (first lactation cows), Group 2 (second lactation cows) and Group 3 (third or more lactations cows). Significant correlations $(\mathrm{P}<0.05)$ are indicated in bold letters

\begin{tabular}{|c|c|c|c|}
\hline & \multicolumn{3}{|c|}{ Locomotion score } \\
\hline & Group $1(n=40)$ & Group $2(n=29)$ & Group $3(n=28)$ \\
\hline Right hind limb medial phalanx X-ray & $\begin{array}{c}\mathrm{r}=-0.1481 \\
\mathrm{P}=0.362\end{array}$ & $\begin{array}{l}\mathrm{r}=0.0491 \\
\mathrm{P}=0.800\end{array}$ & $\begin{array}{l}\mathrm{r}=0.0958 \\
\mathrm{P}=0.628\end{array}$ \\
\hline Right hind limb lateral phalanx X-ray & $\begin{array}{c}r=-0.1368 \\
\mathrm{P}=0.400\end{array}$ & $\begin{array}{l}\mathrm{r}=0.0625 \\
\mathrm{P}=0.747\end{array}$ & $\begin{array}{l}\mathrm{r}=0.1431 \\
\mathrm{P}=0.468\end{array}$ \\
\hline Left hind limb medial phalanx X-ray & $\begin{array}{c}\mathrm{r}=-0.1701 \\
\mathrm{P}=0.294\end{array}$ & $\begin{array}{l}\mathrm{r}=0.1632 \\
\mathrm{P}=0.398\end{array}$ & $\begin{array}{l}\mathrm{r}=0.1992 \\
\mathrm{P}=0.310\end{array}$ \\
\hline Left hind limb lateral phalanx X-ray & $\begin{array}{c}\mathrm{r}=-0.1258 \\
\mathrm{P}=0.439\end{array}$ & $\begin{array}{l}\mathrm{r}=0.0509 \\
\mathrm{P}=0.793\end{array}$ & $\begin{array}{l}\mathrm{r}=0.1431 \\
\mathrm{P}=0.468\end{array}$ \\
\hline WLL & $\begin{array}{l}\mathrm{r}=-0.2170 \\
\mathrm{P}=0.179\end{array}$ & $\begin{array}{l}r=0.1296 \\
\mathrm{P}=0.503\end{array}$ & $\begin{array}{l}\mathrm{r}=0.1877 \\
\mathrm{P}=0.339\end{array}$ \\
\hline SU & $\begin{array}{l}\mathrm{r}=0.0543 \\
\mathrm{P}=0.740\end{array}$ & $\begin{array}{l}\mathrm{r}=0.3116 \\
\mathrm{P}=0.100\end{array}$ & $\begin{array}{l}\mathrm{r}=0.1539 \\
\mathrm{P}=0.434\end{array}$ \\
\hline $\mathrm{SH}$ & $\begin{array}{l}\mathrm{r}=0.0938 \\
\mathrm{P}=0.565\end{array}$ & $\begin{array}{l}\mathrm{r}=0.2751 \\
\mathrm{P}=0.149\end{array}$ & $\begin{array}{l}r=0.0667 \\
P=0.736\end{array}$ \\
\hline $\mathrm{CC}$ & $\begin{array}{c}r=-0.1694 \\
P=0.296\end{array}$ & - & - \\
\hline $\mathrm{HF}$ & $\begin{array}{l}\mathrm{r}=0.1307 \\
\mathrm{P}=0.422\end{array}$ & $\begin{array}{c}\mathrm{r}=0.0104 \\
\mathrm{P}=0.957\end{array}$ & $\begin{array}{l}\mathrm{r}=0.0195 \\
\mathrm{P}=0.922\end{array}$ \\
\hline VF & $\begin{array}{l}\mathrm{r}=0.3518 \\
\mathrm{P}=0.026\end{array}$ & - & - \\
\hline $\mathrm{AF}$ & $\begin{array}{c}\mathrm{r}=-0.3012 \\
\mathrm{P}=0.059\end{array}$ & $\begin{array}{c}\mathrm{r}=-0.0690 \\
\mathrm{P}=0.722\end{array}$ & $\begin{array}{l}r=0.4961 \\
P=0.007\end{array}$ \\
\hline IDH & - & - & $\begin{aligned} \mathrm{r} & =0.0430 \\
\mathrm{P} & =0.828\end{aligned}$ \\
\hline DD & $\begin{array}{l}\mathrm{r}=0.1686 \\
\mathrm{P}=0.298\end{array}$ & $\begin{array}{l}r=0.5674 \\
P=0.001\end{array}$ & $\begin{array}{l}r=0.4389 \\
P=0.019\end{array}$ \\
\hline $\mathrm{HE}$ & $\begin{array}{l}\mathrm{r}=0.0912 \\
\mathrm{P}=0.576\end{array}$ & - & - \\
\hline ID & $\begin{array}{c}\mathrm{r}=-0.0085 \\
\mathrm{P}=0.958\end{array}$ & $\begin{array}{c}\mathrm{r}=0.0032 \\
\mathrm{P}=0.987\end{array}$ & $\begin{array}{c}r=-0.4323 \\
P=0.022\end{array}$ \\
\hline $\mathrm{F}$ & $\begin{array}{l}\mathrm{r}=0.0543 \\
\mathrm{P}=0.740\end{array}$ & $\begin{array}{l}\mathrm{r}=-0.0104 \\
\mathrm{P}=0.957\end{array}$ & $\begin{array}{l}\mathrm{r}=0.2582 \\
\mathrm{P}=0.185\end{array}$ \\
\hline
\end{tabular}

White line lesion (WLL); sole ulcer (SU); sole haemorrhage (SH); corkscrew claw (CC); horizontal fissure or hardship groove (HF); vertical fissure (VF); axial fissure (AF); interdigital hyperplasia (IDH); digital dermatitis (DD); heel erosion (HE); interdigital dermatitis (ID); foot rot, foul or phlegmon (F).

\section{Discussion}

There were no lame cows in our study compared to a study by Frankena et al. (2009) where it was found that almost $18 \%$ of the cows were lame (locomotion score $\geq 3$ ). Locomotion score slightly increased from Group 1 to Group 3, indicating 
the predisposition to a higher risk of lameness in older cows. Similar results were evaluated by Smits et al. (1992), demonstrating that first parity cows were infrequently clinically lame compared to older cows. Groehn et al. (1992) assessed a 30\% augmented risk of becoming lame with the increasing parity number. Reasonable explanations could be the improved occasion for prior foot lesions, arthritis, ligaments breakdown and less agility (Groehn et al., 1992). The incidence of lameness and its correlation to parity is affected by culling practices, but the rising frequency with age could be the effect of elderly and increasing injuries to claw tissue (Sogstad et al., 2005). Bicalho et al. (2007), nevertheless, discovered that digital pressure manifested pain in $5.6 \%, 20.1 \%, 55.5 \%, 79.9 \%$ and $100 \%$ of cows with locomotion score from 1 to 5 respectively, showing that not all painful disorders were identified by the scoring method utilized in our study. Cows are predated animals and bear the pain, in case hiding illness (Sogstad et al., 2012). In our study, in both hind limbs the lateral phalanx showed from Group 1 to Group 3 a progressive statistical prevalence of radiographic changes in respect to the medial one. These results are in agreement with the finding of other authors (El-Shafaey et al., 2013), who described that the lateral digits were more affected than the medial ones. After trimming, the cow's weight is not evenly distributed between the hooves; thus, the lateral hooves carry considerably more weight than the medial ones, this can justify the predisposition of the lateral phalanx to disease (El-Shafaey et al., 2013). Amounts of ground feedback forces showed that in cows the hind limb lateral claws received markedly higher average and maximum vertical pressures than the medial ones (Bicalho and Oikonomou, 2013). Furthermore, Group 3 showed a statistically significant increase of the radiographic changes in the medial phalanx of both hind limbs and in the right hind limb lateral phalanx. WLL, SU, HF and ID were more frequent with increasing parity, this is partly in accordance with numerous studies which discovered more lameness with increasing age (Chesterton et al., 2008; Fjeldaas et al., 2007; Häggman and Juga, 2015). The accumulative result of physiological stress triggered by multiple lactations and any former diseases, especially claw disorders, might induce older cows to new claw disorders. Moreover, increasing parity might lead to increased risk of pressure damage to the sole through defective sole pad structure or sinking pedal bones (Häggman and Juga, 2015), or the consequence of repeated damaging of the corium with permanent and increasing injury to claw tissue (Fjeldaas et al., 2007). In contrast with Kofler et al. (2011), WLL was not the common lesion in these cows. This study, in agreement with Chesterton et al. (2008), also confirmed that age had a significant effect on the relative prevalence of WLL. Furthermore, our results are in contrast with Sanders et al. (2009) who described that later calving decreases the WLL hazard. The percentage of affected animals by SU increased with parity, but was not so evident. These data are in contrast with Laven and Lawrence (2006) and Olechnowicz and Jaśkowski (2010 b) who reported that SU was the most common lesion affecting cattle. Holzhauer et al. (2008) suggested that cow's herd and management factors were associated with the presence of SU. In our study, SH was the most common lesion and this lesion percentage was constant in all our three groups. More sole haemorrhages with increasing age are in contrast to many studies of dairy cattle which found highest odds for $\mathrm{SH}$ in primiparous cows (Chesterton 
et al., 2008; Sogstad et al., 2005). CC was found only in Group 1 and is in contrast with Fjeldaas et al. (2011) who demonstrated that CC was expected with increasing parity and an excessively long trimming interval. Fjeldaas et al. (2011) wrote that the typical corkscrewed claw is usually observed in cows that are more than 3.5 years old. HF percentage increased with parity, VF was only present in Group 1 and AF was present in all three groups with a very low percentage. Fissures might also be caused directly by environmental mechanical influences (Sogstad et al., 2005). IDH was only present in one cow of Group 3, which is an equal low level as recorded in heifers and dairy cows (Kofler et al., 2011). According to Olechnowicz et al. (2010 a), there is a relationship between SU and other claw diseases, such as SH, chronic laminitis, WLL, and IDH. DD was present in high percentage in Group 1 and less in the other two groups. DD is significantly associated with long periods of housing (Chesterton et al., 2008). HE was found only in 1 cow in Group 1. DD, HE and ID are infectious in origin and moisture and dirt are considered to be important predisposing factors (Fjeldaas et al., 2007). In Norway ID is still more prevalent than DD even though DD has been diagnosed in an increased number of Norwegian herds in recent years (Fjeldaas et al., 2011). Our results are in contrast with Fjeldaas et al. (2011), who wrote that HE is usually more extensive the older an animal becomes. F was present in low percentage in all three groups, while Chesterton et al. (2008) recorded the relative prevalence of F. F is the most likely of the common lamenesscausing diseases to be treated by the farmer (Chesterton et al., 2008). In our study a significantly positive correlation was found between locomotion score and VF, AF, DD and ID, nevertheless, Sogstad et al. (2012) described that not all claw lesions lead to an altered locomotion score. In conclusion, this dataset provides an overview of claw lesions in Holstein dairy cows through clinical and radiological observations. Although the data of the present study are obtained from a single farm they are sometimes consistent and other times in contrast with published reports. Using locomotion score to screen herds can be helpful when evaluating claw health and intervention in a herd is needed. Radiographic changes of bone of the digital region in our study were remarkable, so this diagnostic method should be evaluated as an important tool in prevention of supposed future lameness. The overall frequency of claw disorders was comparatively low in this study. Only SH and ID were identified as more prevalent in all three groups, and DD only in Group 1. The results also showed that claw lesions were relatively common, but that unless they were moderately severe there was not always a correlation with locomotion score and all lesions were never associated with lameness. Moreover, the findings of this study suggest that the incidence of claw lesions was not always influenced by the number of parity. They, sometimes, reinforce the importance of looking after first-calving heifers, because this can have important consequences for hoof health in later parity. Therefore, it is important to pay attention to good claw health of the dairy herd, in particular in young cows. Furthermore, claw lesions are a more unmanageable problem and, despite increased interest in the last decade, are still not well understood. 


\section{References}

B i c a lho R.C., Oik o n o m o u G. (2013). Control and prevention of lameness associated with claw lesions in dairy cows. Livest. Sci., 156: 96-105.

B i c a 1 h o R.C., Ch e ong S.H., C r a m e r G., G u a r d C.L. (2007). Association between a visual and an automated locomotion score in lactating Holstein cows. J. Dairy Sci., 90: 3294-3300.

Brzozowska A., Łukaszew ic z M., S ender G., Kolas ińska D., Oprzą dek J. (2014). Locomotor activity of dairy cows in relation to season and lactation. Appl. Anim. Behav. Sci., 156: 6-11.

Chesterton R.N., L aw ren ce K.E., Laven R.A. (2008). A descriptive analysis of the foot lesions identified during veterinary treatment for lameness on dairy farms in north Taranaki. New Zeal. Vet. J., 56: 130-138.

C o o k N.B., N ord l u n d K.V. (2009). The influence of the environment on dairy cow behavior, claw health and herd lameness dynamics. Vet. J., 179: 360-369.

Edmon s o n A.J., L e a n I.J., We a ver L.D., F a r ver T., We b s t e r G. (1989). A body condition scoring chart for Holstein dairy cows. J. Dairy Sci., 72: 68-78.

E 1 - S h a fa e y el-S.A.A., A o k i T., I s h i i M., Y a m a d a K. (2013). Pilot study of bovine interdigital cassetteless computed radiography. J. Vet. Med. Sci., 75: 1503-1506.

Fiore E., Levi M., Gianesella M., Benazzi C., Morgante M., Beltrame A., Vacc a ro C., Gentile A. (2016). Epiphysitis in fattening bulls: Radiological and pathologic findings [Epifisiti nei bovini da carne: reperti radiologici ed anatomopatologici]. Large Anim. Rev., 22: $43-45$.

F jeld a a s T., Nafstad O., Fredriksen B., Ringdal G., S og st a d Å.M. (2007). Claw and limb disorders in 12 Norwegian beef-cow herds. Acta Vet. Scand., 49: 1-11.

F j e l d a a s T., S o g s t a d Å.M., Ø s t e r å s O. (2011). Locomotion and claw disorders in Norwegian dairy cows housed in freestalls with slatted concrete, solid concrete, or solid rubber flooring in the alleys. J. Dairy Sci., 94: 1243-1255.

Frankena K., S omers J.G., S chouten W.G., van S tek J.V., Metz J.H., S ta s s en E.N., $\mathrm{Gr}$ a a t E.A. (2009). The effect of digital lesions and floor type on locomotion score in Dutch dairy cows. Prev. Vet. Med., 88: 150-157.

Green L.E., H edges V.J., S chukken Y.H., B low ey R.W., P a c kington A.J. (2002). The impact of clinical lameness on the milk yield of dairy cows. J. Dairy Sci., 85: 2250-2256.

Gro e h n J.A., K a n e e n e J.B., F o s t e r D. (1992). Risk factors associated with lameness in lactating dairy cattle in Michigan. Prev. Vet. Med., 14: 77-85.

Guccione J., Carcasole C., Alsaad M., D'Andrea L., Di Loria A., De Rosa A., C i a r a mella P., S t e in er A. (2016). Assessment of foot health and animal welfare: clinical findings in 229 dairy Mediterranean buffaloes (Bubalus bubalis) affected by foot disorders. BMC Vet. Res., 12: 107.

H äg g m a n J., J u g a J. (2015). Effects of cow-level and herd-level factors on claw health in tied and loose-housed dairy herds in Finland. Livest. Sci., 181: 200-209.

Holzhauer M., B artels Ch.J.M., Döpfer D., van Schaik G. (2008). Clinical course of digital dermatitis lesions in an endemically infected herd without preventive herd strategies. Vet. J., 177: 222-230.

Kats oulos P.D., Christodoulopoulos G. (2009). Prevalence of lameness and of associated claw disorders in Greek dairy cattle industry. Livest. Sci., 122: 354-358.

K o fle r J. (1999). Clinical study of toe ulcer and necrosis of the apex of the distal phalanx in 53 cattle. Vet. J., 157: 139-147.

K ofler J., Hangl A., Pe s e n h ofer R., L a nd l G. (2011). Evaluation of claw health in heifers in seven dairy farms using a digital claw trimming protocol and claw data analysis system. Berl. Munch. Tierarztl. Wochenschr., 124: 272-81.

L a v e n R.A., L aw re n c e K.R. (2006). An evaluation of the seasonality of veterinary treatments for lameness in UK dairy cattle. J. Dairy Sci., 89: 3858-65.

L i m P.Y., H ux le y a J.N., W i 11 s h i re c J.A., Green a M.J., O th m a n b A.R., K a le r J. (2015). Unravelling the temporal association between lameness and body condition score in dairy cattle using a multistate modelling approach. Prev. Vet. Med., 118: 370-377. 
Momcilovic D., Herbein J.H., Whittier W.D., P olan C.E. (2000). Metabolic alterations associated with an attempt to induce laminitis in dairy calves. J. Dairy Sci., 83: 518-525.

Mülling C., Döpfer D., Edwards T., Larson C., Tomlinson D., Branine M. (2014). Cattle Lameness: Identification, Prevention and Control of Claw Lesions. Zinpro Corporation, pp. 1-75.

O lechnow icz J., Jaśkowski J.M., Antosik P., Bukowska D., Urbaniak K. (2010 a). Claw diseases and lameness in Polish Holstein-Friesian dairy cows. Bull. Vet. I. Pulawy, 54: 93-99.

O le chnow i c z J., J a śk ow s ki J.M. (2010 b). Risk factors influencing lameness and key areas in reduction of lameness in dairy cows. Med. Weter., 66: 507-510.

Rajkondaw ar P.G., Li u M., Dyer R.M., Neerchal N.K., Tas ch U., Lefcourt A.M., Erez B., Varner M.A. (2006). Comparison of models to identify lame cows based on locomotion and lesion scores, and limb movement variables. J. Dairy Sci., 89: 4267-4275.

R o che J.R., Friggens N.C., K a y J.K., F isher M.W., S tafford K.J., B erry D.P. (2009). Invited review: Body condition score and its association with dairy cow productivity, health, and welfare. J. Dairy Sci., 92: 5769-801.

$\mathrm{S}$ a n d e r s A.H., S h e are r J.K., D e Vri e s A. (2009). Seasonal incidence of lameness and risk factors associated with thin soles, white line disease, ulcers, and sole punctures in dairy cattle. J. Dairy Sci., 92: 3165-3174.

S chöpke K., We id ling S., Pijl R., Swalve H.H. (2013). Relationships between bovine hoof disorders, body condition traits, and test-day yields. J. Dairy Sci., 96: 679-689.

Smits M.C.J., Frankena K., Metz J.H.M., Noordhuizen J.P.T.M. (1992). Prevalence of digital disorders in zerograzing dairy cows. Livest. Prod. Sci., 32: 231-244.

S o g s t a d Å.M., F j e l d a a s T., Ø s t e r å s O. (2005). Lameness and claw lesions of the Norwegian red dairy cattle housed in free stalls in relation to environment, parity and stage of lactation. Acta Vet. Scand., 46: 203-217.

S o g s t a d Å.M., F j e l d a a s T., Ø s t e r å s O. (2012). Locomotion score and claw disorders in Norwegian dairy cows, assessed by claw trimmers. Livest. Sci., 144: 157-162.

Tous s a in t R a ven E. (1989). Cattle Footcare and Claw Trimming. Farming Press, Ipswich, UK.

Received: 22 I 2018

Accepted: 10 X 2018 